\title{
Preserving fertility in young patients with lymphoma: an overview
}

\author{
Bansari Patel \\ Brooke V Rossi \\ Division of Reproductive \\ Endocrinology and Infertility, \\ Department of Obstetrics and \\ Gynecology, Case Western Reserve \\ University, Cleveland, OH, USA
}

This article was published in the following Dove Press journal:

Blood and Lymphatic Cancer:Targets and Therapy

18 December 2014

Number of times this article has been viewed
Correspondence: Bansari Patel Division of Reproductive Endocrinology and Infertility, Department of Obstetrics and Gynecology, Case Western Reserve University, I I 100 Euclid Avenue MAC 7007, Cleveland, OH 44106, USA Tel + I 2162855028

Email patelbonnie@gmail.com

\begin{abstract}
Fertility preservation affords patients the ability to reproduce after the initial diagnosis and management of such malignancies as Hodgkin's and non-Hodgkin's lymphoma. Certain chemotherapy regimens and pelvic radiotherapy confer a high-risk of subsequent gonadal compromise in both males and females. Fortunately, early counseling and initiation of fertility-preservation strategies promptly after diagnosis enable patients to maintain hope for future reproduction. Well-established methods for fertility preservation include embryo and oocyte cryopreservation in females and sperm cryopreservation in males. These methods enable patients to utilize assisted reproductive technologies, including in vitro fertilization, at the time of desired childbearing in order to ensure genetic offspring. As most of these modalities are not feasible in some patient populations, including prepubescent patients, newer methods of fertility preservation must be created to ensure the ability to produce genetic offspring in lymphoma patients. This review provides insights into the impact of gonadotoxic treatment on ovarian and testicular function, and highlights current modalities in fertility preservation in both males and females.
\end{abstract}

Keywords: fertility preservation, lymphoma, ART, egg freezing

\section{Introduction}

There will be approximately 80,000 new cases of Hodgkin's and non-Hodgkin's lymphoma in 2014, accounting for 5\% of new cancer cases in the US. ${ }^{1}$ Approximately $12.8 \%$ of patients diagnosed with Hodgkin's lymphoma are under the age of 20 years, and $31 \%$ are between the ages of 20 and 34 years. Conversely, only $1.6 \%$ of patients diagnosed with non-Hodgkin's lymphoma are under the age of 20 years, and 3.8\% are between the ages of 20 and 34 years. Overall, it is estimated that Hodgkin's and non-Hodgkin's lymphomas comprise $8 \%$ of childhood carcinomas. ${ }^{2}$ Unlike most carcinomas, surgical therapy is not the mainstay in treatment of most lymphomas, and therapeutics usually consist of chemotherapy, radiation therapy, and biologic agents, such as monoclonal antibodies, proteasome inhibitors, and epigenetic modulators. ${ }^{3-5}$ Of these, depending on the aggressiveness and stage of the cancer, chemotherapy, radiation therapy, or a combination of the two is most commonly utilized in treatment of these cancers. ${ }^{6,7}$

Due to the need for gonadotoxic chemotherapy and radiotherapy, these patients are at a higher risk for premature ovarian failure (POF) or hypergonadotropic hypogonadism than people who have not received these therapies. POF occurs when all primordial follicles are destroyed prior to the age of 40 years. As a result, hypoestrogenism ensues, resulting in permanent amenorrhea and infertility despite compensatory 
elevated levels of follicle-stimulating hormone (FSH), usually $>30 \mathrm{mIU} / \mathrm{mL} .{ }^{8}$ The rate of POF in childhood cancer survivors approaches $8 \%$, compared to $1 \%$ in the general population. ${ }^{9}$

While fertility may be impaired in all patients exposed to gonadotoxic chemotherapy and radiotherapy, some studies specifically address these risks in lymphoma patients. van der Kaaij et al reported that patients with both Hodgkin's and non-Hodgkin's lymphoma are less likely to conceive posttreatment compared to healthy controls. ${ }^{10}$ Additionally, childhood cancer survivors with Hodgkin's or non-Hodgkin's lymphoma have an approximately 2-fold-higher risk of infertility compared to their healthy siblings. ${ }^{11}$ Childhood cancer survivors also have worse pregnancy outcomes compared to infertile controls with assisted reproductive technology (ART), including in vitro fertilization (IVF). ${ }^{12}$ Indeed, clinical pregnancy and live-birth rates with ART are approximately $70 \%$ lower in childhood cancer survivors compared to infertile controls when ART is performed after gonadotoxic therapy. The utilization of fertility-preservation options, including ART, prior to treatment may enable patients to optimize fertility outcomes and mitigate the impact of cytotoxic therapy on future childbearing. Biologic parenthood is possible for many men and women who will lose reproductive function during the treatment of lymphoma. Therefore, addressing fertility preservation with young patients diagnosed with lymphoma should be an essential aspect of their comprehensive care.

Pretreatment counseling should involve the potential impact of chemoradiation on future gonadal function and childbearing. Options for fertility preservation, associated costs, and their efficacy should be discussed as well. This discussion should occur soon after diagnosis, as some treatment options may take up to 10-12 days, possibly delaying the initiation of cancer treatment. Additionally, early consultation with a reproductive endocrinologist or fertility specialist is recommended.

Fertility preservation requires individualization. The optimal approach depends on the type of disease, chemotherapy utilized, the need for radiation therapy, and time available before initiation of treatment. Additionally the patient's sex, age, and costs should be considered.

The following review will outline basic female and male reproductive physiology. The adverse effects of gonadotoxic chemotherapy and radiotherapy on ovarian and testicular function will be addressed. Additionally, we will outline the currently available strategies for fertility preservation in both females and males afflicted with lymphoma.

\section{Women}

\section{Female reproductive physiology}

Oogenesis is initiated during fetal development, with a human female's peak number of oocytes occurring at approximately 20 weeks gestational age, with approximately 7 million immature primary oocytes present at the time. ${ }^{13}$ This number is drastically reduced secondary to apoptosis, and only approximately 1-2 million oocytes remain at the time of birth. These oocytes are arrested in the prophase stage of meiosis I until ovulation after the onset of puberty. ${ }^{14}$ These arrested immature primary oocytes are continually destroyed by atresia, and there is attrition of an additional $25 \%$ of oocytes until the initiation of puberty.

In the prepubertal state, ovarian function is suppressed due to low levels of hypothalamus-secreted gonadotropinreleasing hormone agonists (GnRH-as)..$^{15}$ Therefore, the gonadotropins, FSH, and luteinizing hormone (LH) are not synthesized and released from the anterior pituitary in this state. In this stage of life, the ovaries are quiescent due to the lack of hormonal stimulation. Pulsatile GnRH activity during puberty results in the release of FSH and $\mathrm{LH}$, and ovarian activity ensues. ${ }^{16}$

At all stages of life prior to menopause, immature oocytes are enveloped in quiescent primordial follicles. Recruitment of primordial follicles and development of the oocyte within these immature follicles is gonadotropinindependent and relies on a host of growth factors. Each cycle, a cohort of primordial follicles is recruited to grow, and after attrition only a handful will reach the gonadotropin-dependent stages of advanced growth. Only one follicle from this cohort will attain dominance and ovulate each cycle. At the time of ovulation, an oocyte will complete meiosis through metaphase II arrest until fertilization with sperm.

\section{Effects of chemotherapy on female fertility}

Most chemotherapeutic agents work by affecting cell-cycle division. ${ }^{17}$ Therefore, it can be anticipated that anticancer agents would likely affect oocytes entering a phase of maturation, as well as the growth and proliferation of the somatic cells that support the oocyte within individual ovarian follicles. This mechanism explains the immediate cessation of menses after chemotherapy initiation in postpubertal women. ${ }^{17}$ This acute disruption in reproductive hormone levels may resolve upon the cessation of chemotherapy without a long-term impact on future fertility. 
The impact of chemotherapy on quiescent immature follicles that have not been recruited from growth remains poorly understood. Certain chemotherapeutic agents may affect these immature follicles oocytes, due to their effects on quiescent cells. Alkylating agents, for instance, have a non-cycle-specific mechanism of action leading to single- and double-strand deoxyribonucleic acid (DNA) breaks, thereby potentially affecting both quiescent and dividing cells in the ovary (Table 1). ${ }^{18,19}$ Alkylating agents may also induce cortical fibrosis and blood-vessel damage in ovarian tissue. ${ }^{20}$ Cyclophosphamide and procarbazine are particularly toxic to the ovaries, and may adversely affect future fertility. ${ }^{21}$ Anthracyclines, such as doxorubicin, and certain platinum agents also confer a high risk of gonadotoxicity. ${ }^{22}$

As previously mentioned, biologic therapies, such as proteasome inhibitors and monoclonal antibodies, are also commonly used for the treatment of lymphomas. ${ }^{3,4}$ Unfortunately, there is a paucity of data with regard to the long-term impact of these drugs on gonadal function.

\section{Common regimens in Hodgkin's lymphoma}

The ABVD (adriamycin, bleomycin, vinblastine, dacarbazine) regimen used in Hodgkin's lymphoma is associated with a POF rate of less than $10 \%$ in the reproductive age. ${ }^{7}$ Conversely, POF rates with the BEACOPP (bleomycin, etoposide, adriamycin, cyclophosphamide, oncovin, procarbazine, prednisone) regimen exceed $50 \%$ in the reproductive age. Similarly, MOPP (mechlorethamine, oncovin, procarbazine, prednisone) regimens are associated with POF rates of
20\%-50\%. Hematopoietic stem cell transplants (HSCTs) are associated with the highest rates of POF, due to the requirement for conditioning with high-dose chemotherapy with or without total-body irradiation in these patients. ${ }^{23}$ Ultimately, $70 \%-100 \%$ of patients undergoing HSCTs will have POF. ${ }^{24}$

\section{Common regimens in non-Hodgkin's lymphoma}

The CHOP (cyclophosphamide, hydroxydaunorubicin, oncovin, prednisone) regimen is associated with POF rates of approximately $5 \%$, with pregnancy rates exceeding $50 \%$ after treatment. ${ }^{25}$ Hyper-CVAD (cyclophosphamide, vincristine, adriamycin, dexamethasone, cytarabine, methotrexate) confers POF rates of approximately $14 \%$, and consequent pregnancy rates after treatment are approximately $43 \%{ }^{26}$ Similarly to Hodgkin's lymphoma, POF rates after HSCT are approximately $70 \%-100 \% .^{24}$

The cumulative dose of the cytotoxic drug being administered is a key factor impacting permanent ovarian failure. Goldhirsch et al demonstrated a steadily increasing rate of POF, ranging from $10 \%$ to $61 \%$ as the cumulative dose of cyclophosphamide increased. ${ }^{27}$ Older women in particular are susceptible to gonadotoxic agents, with one study reporting POF rates approaching 34\% in Hodgkin's lymphoma survivors over the age of $30 .{ }^{28}$ Lower cumulative doses of cytotoxic drugs are required for older women to experience amenorrhea compared to younger women. In one study, all women above the age of 40 years had permanent amenorrhea after receiving more than $5.2 \mathrm{~g}$ of cyclophosphamide, whereas the dose required to

Table I Effect of cell-cycle-specific and -nonspecific agents on ovarian function

\begin{tabular}{|c|c|c|c|c|}
\hline Drug Type & $\mathbf{G}_{1}$ & $\mathbf{S}$ & $\mathbf{G}_{2}$ & M \\
\hline \multicolumn{5}{|c|}{ Cell-cycle-specific agents } \\
\hline \multirow[t]{5}{*}{ Drug } & L-Asparaginase & Cytarabine & Bleomycin & Vinblastine \\
\hline & Prednisone & 5-Fluorouracil & Etoposide & Vincristine \\
\hline & & Hydroxyurea & & Paclitaxel \\
\hline & & Methotrexate & & \\
\hline & & Thioguanine & & \\
\hline Ovarian damage & No/low risk & No/low risk & No/low risk & No/low risk \\
\hline Drug type & Alkylators & Antitumor antibiotics & Nitrosoureas & Miscellaneous \\
\hline \multicolumn{5}{|c|}{ Cell-cycle-nonspecific agents } \\
\hline \multirow[t]{8}{*}{ Drug } & Cyclophosphamide & Dactinomycin & Carmustine & Dacarbazine \\
\hline & Ifosfamide & Daunorubicin & Lomustine & Procarbazine \\
\hline & Carboplatin & Doxorubicin & Streptozotocin & \\
\hline & Cisplatin & Mitomycin & & \\
\hline & Busulfan & Mitoxantrone & & \\
\hline & Chlorambucil & & & \\
\hline & Mechlorethamine & & & \\
\hline & Melphalan & & & \\
\hline Ovarian damage & High & Intermediate & Intermediate & High \\
\hline
\end{tabular}

Note: Data from Devita et al. ${ }^{19}$ 
cause amenorrhea in younger women was 9.5 g. ${ }^{29}$ Similarly, prepubertal girls seem to be less susceptible than others to cytotoxic drugs. ${ }^{30}$ Prepubertal girls may be able to tolerate up to $50 \mathrm{~g}$ of cyclophosphamide without adverse effects on longterm ovarian function. Previous studies have demonstrated posttreatment menarche and subsequent ovulatory cycles in prepubertal women undergoing even cytotoxic chemotherapy. ${ }^{31}$ As such, it can be postulated that the higher the number of primordial follicles in a patient, the greater the prognosis in terms of preserved ovarian function. The prepubescent stage confers protection against gonadotoxicity, due to the presence of a larger pool of primordial follicles which are in a state of metabolic quiescence, thus reducing the deleterious effects of cytotoxic chemotherapy on the ovaries.

\section{Radiotherapy-induced ovarian failure}

Radiation therapy utilized in the treatment of lymphoma may also have deleterious effects on future fertility. Total-body irradiation, direct pelvic, abdominal, and spinal irradiation or scatter irradiation, in doses as low as 1-2 Gy in girls ${ }^{32}$ and $4-6$ Gy in adults, ${ }^{33}$ can have a permanent negative effect on the ovaries by causing the depletion of follicles. Irradiation results in ovarian atrophy and reduced follicle stores. ${ }^{34}$ On the cellular level, oocytes show rapid onset of pyknosis, chromosome condensation, disruption of the nuclear envelope, and cytoplasmic vacuolization. Serum levels of FSH and LH rise progressively within 4-8 weeks following radiation exposure, along with a decline in serum $\mathrm{E}_{2}$ levels, implying POF. Indeed, in the Childhood Cancer Survivor Study, pelvic radiation was found to be a significant risk factor for both acute ovarian failure and premature menopause. ${ }^{21}$

The degree and persistence of ovarian damage and suppression of ovarian function is related to the patient's age and the cumulative dose of ionic radiation to the ovaries (Table 2). ${ }^{34,35}$ Similarly to chemotherapy exposure, older age

Table 2 Effect of radiotherapy on ovarian function

\begin{tabular}{|c|c|c|}
\hline \multirow{2}{*}{$\begin{array}{l}\text { Ovarian } \\
\text { dose (cGy) }\end{array}$} & \multicolumn{2}{|l|}{ Risk of ovarian failure } \\
\hline & Women aged I 5-40 years & Women $>40$ years \\
\hline$<60$ & No adverse effects & No adverse effects \\
\hline 150 & $\begin{array}{l}\text { Minimal adverse effects in } \\
\text { young women }\end{array}$ & $\begin{array}{l}\text { Some risk of sterilization } \\
\text { in women over } 40 \text { years }\end{array}$ \\
\hline $250-500$ & $\begin{array}{l}60 \% \text { sterilized; remainder } \\
\text { may experience transient } \\
\text { amenorrhea }\end{array}$ & $100 \%$ sterilized \\
\hline $500-800$ & $\begin{array}{l}60 \%-70 \% \text { sterilized; } \\
\text { remainder may experience } \\
\text { transient amenorrhea }\end{array}$ & $100 \%$ sterilized \\
\hline$>800$ & $100 \%$ sterilized & $100 \%$ sterilized \\
\hline
\end{tabular}

Note: Data from Damewood and Grochow. ${ }^{34}$ confers an increased risk. An effective sterilizing radiation dose at birth is estimated to be $20.3 \mathrm{~Gy}$, while that number decreases to 14.3 Gy by 30 years of age. ${ }^{36}$ Increasing cumulative doses of radiation and the schedule of delivery also determine the ultimate degree of ovarian damage. ${ }^{37}$ Specifically, irradiation is more toxic when given in a single dose compared to fractionated doses..$^{38}$ Radiation doses as low as 2 Gy may cause ovarian damage. ${ }^{32}$ Another study found ovarian failure rates of $11 \%-13 \%$ in women exposed to less than 3 Gy of radiation. Conversely, ovarian failure rates approached $60 \%-63 \%$ in women exposed to greater than 3 Gy. ${ }^{39}$ Irradiation doses approaching 14-30 Gy may also cause permanent damage to uterine musculature and vessels, thereby potentially impeding the ability of a survivor to carry a full-term pregnancy. ${ }^{40,41}$

Concerns regarding pregnancy outcomes after pelvic irradiation have been addressed in the literature. Fenig et al reported an increased incidence in low birth weight and spontaneous abortions if pregnancy occurred within 1 year of irradiation. ${ }^{42}$ Therefore, they recommended that pregnancy be delayed for at least 1 year after completion of radiation. Similarly, others have reported a small but absolute increase in adverse pregnancy outcomes in childhood cancer survivors, including those inflicted with Hodgkin's and non-Hodgkin's lymphoma. ${ }^{43,44}$ The literature is not consistent with respect to this issue, however, as other studies have not found a similar increase in adverse pregnancy outcomes. De Sanctis et al reported no significant association between radiotherapy treatment and adverse birth outcomes, such as spontaneous abortions, premature birth and low birth weight, in Hodgkin's lymphoma survivors..$^{45}$ Additionally, Swerdlow et al reported no increase in stillbirths, low birth weight, congenital malformations, abnormal karyotypes, or cancer in the offspring of patients who underwent pelvic irradiation for Hodgkin's disease. ${ }^{46}$

Ultimately, as previously mentioned, chemotherapy- and radiotherapy-induced gonadal dysfunction depends on the age at first treatment and the treatment protocols. Therefore, it should be emphasized that all counseling on reproductive risks and options to preserve fertility after treatment must be individualized.

\section{Strategies to preserve fertility in females}

A wide array of options are available for preservation of fertility in patients affected by lymphoma. Unfortunately, many of the available techniques are experimental and based only on case reports, retrospective studies, and expert opinions. 


\section{Pharmacologic protection}

As prepubertal females are the least susceptible to gonadotoxic therapies, administration of $\mathrm{GnRH}-\mathrm{as}$ to mimic this state may prevent $\mathrm{POF}^{47}$ Indeed, there is some evidence in murine and rat models that adjuvant treatment with GnRH-as may protect gonads from the deleterious effects of chemotherapy. ${ }^{48,49}$ Some retrospective studies have demonstrated a protective effect of $\mathrm{GnRH}$-as against ovarian failure when initiated prior to chemotherapy ${ }^{50}$ However, there is controversy with regard to their efficacy in humans. To date, 20 studies (five prospective randomized controlled trials [RCTs] and 15 non-RCTs) comprising 1,837 patients have reported benefits of GnRH-a therapy during chemotherapy in various types of cancers with different chemotherapeutics with respect to prevention of ovarian failure. ${ }^{51,52}$ Overall, patients treated with GnRH-as concurrently with chemotherapy preserved their cyclic ovarian function in $91 \%$ of cases compared to $41 \%$ of controls, with a pregnancy rate of $19 \%-71 \%$ in the treated patients in non-RCTs. Furthermore, seven meta-analyses consisting of RCTs and non-RCTs reported decreased rates of ovarian failure in $\mathrm{GnRH}$-a-treated women compared to controls. ${ }^{6,47,53-57}$ It should be noted, however, that most of these meta-analyses have included some RCTs and non-RCTs with methodological flaws. For instance, some included studies had short term follow-up of patients, some as short as 3 months after cessation of chemotherapy. Due to the acute effects of chemotherapy on cyclic ovarian function, few conclusions can be drawn from studies with such a short-term follow-up. Additionally, length of follow-up differed between treatment and control groups in some studies included, and definitions of ovarian failure were not uniform across studies. Most studies did not examine the effects on future fertility in these patients either, thus limiting our ability to draw significant conclusions in this regard.

Indeed, some authors have questioned the use of $\mathrm{GnRH}$-as for gonadal suppression. Since primordial follicles that are primarily affected during chemotherapy are quiescent and their recruitment is gonadotropin-independent, the need for gonadal suppression is called into question. ${ }^{58}$ As significant controversy regarding the utility of $\mathrm{GnRH}$-as for prevention of ovarian failure exists in the literature, efforts should be made to counsel patients on methods with greater efficacy in preserving fertility. ${ }^{59,60}$ It is important to note, however, that while GnRH-as may not definitively provide a protective effect on future ovarian function, they may facilitate menstrual cessation in patients with anemia as a result of lymphoma. Anemia is a relatively common occurrence in lymphoma patients as a consequence of both lymphoproliferation and administration of cytotoxic therapy. As such, GnRH-a utilization may be beneficial to ameliorate symptoms of severe anemia through complete cessation of cyclic blood loss during menstruation. ${ }^{61}$

\section{Ovarian transposition}

Ovarian transposition or oophoropexy may enable preservation of ovarian function after pelvic radiotherapy. Surgically transposing the ovaries outside the field of radiation may reduce the ovarian exposure by $5 \%-10 \%$ compared to in situ ovaries. ${ }^{62}$ Initially, lateral ovarian transposition required laparotomy, division of bilateral utero-ovarian ligaments, and subsequent reposition and suture fixation of bilateral tubes and ovaries to ipsilateral paracolic gutters. Transposing the ovaries in this manner to the lateral paracolic gutters enables them to rest approximately $3 \mathrm{~cm}$ above the upper border of the radiation field, a distance that has been shown to minimize harm to ovaries. ${ }^{63}$ Indeed, ovarian failure may result if the ovaries are not moved far enough out of the radiation field, or if they migrate back to their original position. Oophoropexy is now commonly performed through a laparoscopic approach, thereby minimizing patient burden ${ }^{64}$ In addition to expediting patient recovery, laparoscopic oophoropexy also offers the ability to initiate radiotherapy soon after surgery. Expediting radiotherapy may prevent ovarian damage as a result of ovaries migrating back to the pelvis, thus obviating the need for additional procedures to retranspose ovaries out of the radiation field. Laparoscopic ovarian transposition may preserve ovarian function in approximately $85 \%$ of patients aged under 40 years with normal ovarian reserve (relative supply of remaining oocytes) prior to treatment. Similarly, Terenziani et al reported 14 pregnancies in eleven girls afflicted with Hodgkin's lymphoma who underwent oophoropexy at the age of $13 .{ }^{65}$

\section{Assisted reproductive technology}

Patients also have the option of preserving gamete function ex vivo prior to initiation of gonadotoxic chemoradiation with ART. ART affords patients the opportunity to cryopreserve either embryos or mature oocytes for future utilization. Other options include ovarian tissue and immature oocyte cryopreservation, which are still considered to be experimental.

\section{Embryo cryopreservation}

Embryo cryopreservation is an established technology that offers fertility, regardless of posttreatment gonadal function. Studies on exact pregnancy rates of lymphoma 
patients undergoing embryo cryopreservation are limited. Approximate pregnancy and live-birth rates for these patients may be inferred from infertile and donor populations (Table 3). ${ }^{66}$ The Society for Assisted Reproductive Technology (SART) compiles national and clinic-specific data with regard to these outcomes. ${ }^{66}$ As oocyte donors are generally young and presumably fertile, young lymphoma patients without a known history of infertility at the time of embryo cryopreservation would presumably have comparable pregnancy and live-birth rates as oocyte donors. In contrast, pregnancy and live-birth rates for older patients may be inferred from data from age-matched infertile couples, with the understanding that these data may have limitations, since these patients may not have infertility prior to gonadotoxic treatment. In general, postthaw survival rates of cryopreserved embryos range between $35 \%$ and $90 \% .{ }^{67}$ If multiple embryos are available for cryopreservation, cumulative pregnancy rates are in the order of $60 \%$. The prognosis of future fertility with embryo cryopreservation is dependent on the age of the patient. Live-birth rates from cryopreserved embryos are highest among patients under the age of 35 years, at approximately $42 \%$ per cycle (Table 3 ). Cryopreserved embryos from donor oocytes result in a livebirth rate of approximately $37 \%$.

However, direct comparisons of live-birth rates between the infertile population/donors and patients with lymphoma must be made judiciously, as recent data show that patients afflicted with both Hodgkin's and non-Hodgkin's lymphoma have lower ovarian reserves retrieved at baseline than healthy age-matched controls. ${ }^{68}$ Furthermore, both types of lymphoma patients had significantly fewer oocytes retrieved than patients undergoing oocyte retrieval for breast cancer. Therefore, the diagnosis of lymphoma may confer disadvantages with respect to oocyte stimulation and thus embryo cryopreservation. However, due to a paucity of data on specific outcomes on lymphoma patients and despite these limitations of inference, national SART data may be the best-available option for counseling patients for fertility preservation prior to initiation of gonadotoxic therapy.
Embryo cryopreservation consists of undergoing controlled ovarian stimulation with gonadotropins lasting approximately 7-11 days. Serial transvaginal ultrasounds are utilized to measure oocyte response to stimulation. Once oocytes reach the appropriate size and are deemed mature, patients undergo retrieval of mature oocytes. Fertilization with sperm takes place using conventional IVF or intracytoplasmic sperm injection, utilizing either a slow-freeze method or ultrarapid vitrification. ${ }^{69}$ Embryos can then be thawed and transferred to the uterus after completion of lymphoma treatment. The need for viable sperm is integral for embryo formation. As such, women without partners may opt to utilize sperm donors in order to accomplish fertilization. However, while this option offers excellent clinical outcomes, it may not be feasible to cryopreserve embryos from all patients, such as prepubescent girls, adolescent girls, or women without a partner who do not desire to utilize donor sperm. As such, other modalities for fertility preservation must be utilized in these patients.

\section{Mature oocyte cryopreservation}

For adolescent girls and women, mature oocyte cryopreservation may be more suitable than embryo cryopreservation. Early studies in mature oocyte cryopreservation yielded disappointing results with respect to oocyte survival, fertilization, and subsequent pregnancy rates. A variety of cellular and subcellular structures of the human oocyte, such as the zona pellucida and mitotic spindle, appear to be very sensitive to damage from cryopreservation. ${ }^{70}$ However, the introduction of ultrarapid vitrification has improved success rates of mature oocyte cryopreservation tremendously. ${ }^{70-72}$ With improvements in vitrification, postthaw survival rates of cryopreserved oocytes approach those seen with embryo cryopreservation. ${ }^{73-75}$ Porcu et al reported outcomes on 18 patients who underwent mature oocyte cryopreservation secondary to the requirement of gonadotoxic treatment. ${ }^{76}$ A 4-year patient follow-up revealed successful pregnancies after rapid cryopreservation of oocytes and subsequent thawing and fertilization. Pregnancy even occurred with oocytes that had been cryopreserved for years. Similarly, a recent

Table 32012 National in vitro fertilization live-birth rates per embryo transfer

\begin{tabular}{|c|c|c|c|c|c|c|}
\hline & \multicolumn{6}{|c|}{ Age (years) } \\
\hline & Oocyte donor & $<35$ & $35-37$ & $38-40$ & $41-42$ & $>42$ \\
\hline Fresh-cycle live birth per ET (\%) & 56.6 & 47.1 & 37.9 & 28.5 & 16.3 & 6.1 \\
\hline Cryopreserved/thawed-cycle live birth per ET (\%) & 37.2 & 42.4 & 39.8 & 33.9 & 26.4 & 17.8 \\
\hline Average number of embryos transferred & 1.8 & 1.8 & 1.8 & 1.8 & 1.9 & 2.0 \\
\hline
\end{tabular}

Note: Data from Society for Assisted Reproductive Technology. ${ }^{66}$ 
double-blinded RCT comprising 600 patients who underwent either IVF using fresh oocytes or mature cryopreserved oocytes noted no differences in pregnancy rates between the two modalities. ${ }^{74}$ As such, mature oocyte cryopreservation is no longer considered experimental. ${ }^{77}$

Similarly to embryo cryopreservation, pregnancy rates following oocyte-cryopreservation decline with advancing age of the woman. ${ }^{78}$ The process of controlled ovarian stimulation and oocyte retrieval required for mature oocyte cryopreservation is similar to the process of obtaining mature oocytes for embryo cryopreservation.

\section{Cryopreservation and transplantation of ovarian tissue}

Ovarian tissue cryopreservation and transplantation is an experimental procedure introduced to preserve fertility in women with threatened reproductive potential. Cryopreservation of cortical tissue may enable preservation of fertility in prepubescent females and females who are unable to delay treatment, and dispense the time necessary for undergoing embryo or oocyte cryopreservation. ${ }^{79}$ Either laparoscopy or laparotomy can be utilized to obtain ovarian cortical tissue. Ovarian tissue is then cryopreserved using slow-freeze or ultrarapid vitrification. Upon completion of gonadotoxic therapy and at the time of desired childbearing, cryopreserved ovarian tissue can be thawed and implanted near the fallopian tube in an orthotopic fashion (physiologic location), allowing spontaneous ovulation and natural conception to take place. ${ }^{80,81}$ In 2004, Donnez et al reported a case of a woman with stage IV Hodgkin's lymphoma who underwent ovarian cortex biopsy and cryopreservation prior to the initiation of chemotherapy. ${ }^{80}$ The patient underwent orthotopic autotransplantation of freeze-thawed tissue 6 years after completion of therapy. Within 5 months of transplantation, the patient resumed monthly ovulation, as evidenced by a dominant follicle and monthly menstrual cycles. The patient spontaneously conceived an intrauterine pregnancy 11 months after ovarian tissue reimplantation. Similarly, numerous investigators have reported 24 spontaneous ovarian functions and pregnancies after 60 cases of ovarian cortex cryopreservation and subsequent orthotopic tissue reimplantation. ${ }^{81-90}$ Ovarian tissue can also be reimplanted in a heterotopic (on the abdominal wall) location, necessitating ART for potential conception. ${ }^{81}$

Freezing cortical ovarian tissue does present some challenges. Unlike a suspended single cell, tissue cryopreservation presents serious physical constraints related to heat and mass transfer and the potential formation of ice crystals, rendering the tissue susceptible to freeze-thaw injury. ${ }^{91}$
While cortical ovarian tissue cryopreservation, thawing, and heterotopic transplantation followed by subsequent IVF have resulted in live births in animals, no live births have been reported in humans. ${ }^{92}$ However, cortical ovarian tissue cryopreservation and subsequent autologous orthotopic transplantation has been successfully performed in humans, with resultant spontaneous conception and live births. ${ }^{82}$ To date, six spontaneous pregnancies, resulting in seven live births, have been described in both Hodgkin's and non-Hodgkin's lymphoma patients who underwent this modality for fertility preservation. ${ }^{60}$ Ovarian tissue function and spontaneous ovulation generally resumes between 60 and 240 days after orthotopic tissue reimplantation and lasts up to approximately 7 years. ${ }^{7,93}$ Therefore, this modality may provide little hope toward ensuring long-term preservation of fertility after gonadotoxic treatment. As such, no live births have been reported in prepubescent girls who have undergone ovarian tissue cryopreservation at young ages. ${ }^{60}$ However, as these patients have not undergone subsequent postthaw ovarian autotransplantation due to their young ages, few definitive conclusions can be made about the efficacy of this modality in fertility preservation in prepubescent patients. ${ }^{94}$

There are some limitations to ovarian tissue cryopreserva tion. Similarly to embryo and mature oocyte cryopreservation, the prognosis of ovarian tissue cryopreservation declines with age, and it may not be feasible in patients older than 40 years. ${ }^{95}$ Additionally, concerns of reseeding cancerous tissue exist in autologous ovarian tissue reimplantation. While this risk appears to be higher in certain systemic conditions, such as leukemia, there have been no reports of reseeding and subsequent recurrence in lymphoma patients..$^{96,97}$ Other concerns include the loss of a large fraction of follicles during ovarian tissue cryopreservation secondary to initial ischemia after transplantation. ${ }^{98}$ For this reason, there may be some utility of ovarian transplantation using a vascular graft. Due to a paucity of robust data with respect to long-term outcomes and safety of ovarian tissue cryopreservation, this modality is currently considered to be investigational, and should only be offered to patients after extensive counseling and referral to physicians with expertise in this procedure.

\section{In vitro maturation of immature oocytes}

In vitro maturation (IVM) refers to the maturation of immature oocytes in culture after their recovery from small antral follicles at early stages prior to selection and dominance. IVM of human oocytes was first reported in 1965, followed by successful pregnancy and delivery reported in $1989 .{ }^{99}$ Folliculogenesis to early antral stages occurs independently of 
gonadotropins. IVM can be performed urgently irrespective of the phase of the menstrual cycle without affecting the quantity and maturation rate of the oocytes. Therefore, this modality may be beneficial for patients who are unable to undergo controlled ovarian stimulation due to time constraints prior to initiation of gonadotoxic therapy. Exposure to gonadotropins and supraphysiologic levels of estradiol as a result of controlled ovarian stimulation may be detrimental to patients with estrogen-responsive carcinomas and patients predisposed to ovarian hyperstimulation (such as young patients with polycystic ovarian syndrome). ${ }^{100,101}$ This approach also has fewer associated costs than controlled ovarian stimulation, as it does not involve expensive gonadotropin injections. Unfortunately, despite these advantages, maturation rates and the developmental potential of embryos derived from IVM oocytes are significantly lower than those of oocytes matured in vivo. Moreover, pregnancy rates with IVM are low compared with controlled ovarian stimulation with embryo/ oocyte cryopreservation. ${ }^{60,102}$ As a result of these challenges, IVM is considered to be an investigational modality for fertility preservation.

\section{Special considerations}

\section{Prepubertal females}

Fertility preservation in children and prepubertal adolescents remains a challenge. Unfortunately, well-established methods of fertility preservation in postpubertal females, such as embryo and mature oocyte cryopreservation, are not feasible in this patient population. ${ }^{103,104}$ Prepubertal females are a unique subgroup of the fertility-preservation population in that they are commonly too young to understand the full scope of their disease and its implications on future fertility. As these patients have not yet commenced the hormonal changes associated with puberty and hypothalamic-pituitary-ovarian axis maturation, treatment options are limited. Cortical ovarian tissue cryopreservation and subsequent transplantation is the only modality that is efficacious for this patient population. ${ }^{94}$ Unfortunately, to date there have been no reports of live births from ovarian tissue harvested prepubertally, due primarily to the young age of the patients at the time of treatment. In animals, however, IVM from immature oocytes harvested from ovarian tissue has yielded both successful embryo development and live births. ${ }^{105-112}$ Fortunately, to ape these results in humans, improvements in IVM techniques in humans are at the fore of fertility-preservation research, and may be another option for fertility preservation in this population in the future.

\section{Men}

\section{Male reproductive physiology}

Spermatogenesis in the seminiferous tubules begins at puberty, and results in the transformation of immature germ cells into mature spermatozoa. Prior to pubertal development, the testis of a 10 -year-old male is estimated to contain $83,000,000$ diploid germ cells. ${ }^{113}$ The process of transformation from spermatogonia to spermatozoa includes mitosis and two rounds of meiotic divisions over a period of approximately 74 days. Progenitor spermatogonia that remain mitotically active throughout the lifelong process of spermatogenesis are the most susceptible to gonadotoxic insult. ${ }^{114}$ Successful completion of differentiation to mature spermatozoa is highly dependent on the specialized intratesticular microenvironment and hormonal milieu. At puberty, GnRH is released by the hypothalamus in a pulsatile fashion, which subsequently induces release of FSH and LH by the anterior pituitary gland. ${ }^{115} \mathrm{FSH}$ predominantly acts on Sertoli cells to promote spermatogenesis, whereas LH targets intratesticular Leydig cells to produce testosterone. Sertoli cells produce multiple regulating substances, such as anti-Müllerian hormone (during fetal life) and inhibin (negative feedback to FSH secretion) to regulate the hypothalamic-pituitary axis. Similarly, Leydig cell-produced testosterone provides negative feedback to pituitary secretion of LH.

\section{Effects of gonadotoxic therapy on testicular function}

Male infertility associated with lymphoma and other malignances may occur due to a myriad of factors, including the malignancy itself, radiation, gonadotoxic chemotherapy, or a combination of these factors. Although the underlying mechanism has not been fully elucidated, certain malignancies, including lymphomas, may have an adverse effect on testicular function in and of themselves. ${ }^{116,117}$ Rueffer et al reported reduced semen quality in $70 \%$ of males with Hodgkin's lymphoma. ${ }^{118}$ Some patients with lymphoma present with baseline oligospermia (low sperm count), azoospermia (absent sperm), or sperm chromosomal aneuploidy. ${ }^{118,119}$ However, following treatment of their malignancy, some of these patients may experience improvement in semen parameters. These findings implicate the primary malignancy or the immune response to the cancer as a contributing factor to impaired fertility in these patients. ${ }^{120,121}$ Additionally, both radiation and chemotherapy may result in damage to the seminiferous tubules, including spermatogonial cells and Sertoli cells, with resultant 
detrimental effects on fertility. Active and inactive germ cells are also susceptible to gonadotoxic insult, possibly inducing permanent infertility. ${ }^{122,123}$ This susceptibility to gonadotoxic insult may occur at all ages, including before puberty. ${ }^{124}$ However, recovery may be possible. The degree of recovery attained depends on several factors, including the type of therapy, dose, and fractionation/delivery schedule. ${ }^{125}$ Fortunately, in contrast to the seminiferous epithelium where spermatogenesis occurs, Leydig cells are relatively resistant to gonadotoxicity from chemoradiation, and hence cancer treatments rarely result in clinical hypogonadism. ${ }^{126}$

While little is known about the impact of biologic therapies, such as anti-20 monoclonal antibodies and proteasome inhibitors, on testicular function in humans, recent evidence in mice suggests that proteasome inhibitors may have longterm adverse effects on sperm concentrations, testicular weight, and Sertoli cell dysfunction, evidenced by persistently increased FSH levels. ${ }^{127}$ Long-term studies in humans are needed, however, in order to delineate the effects of these therapies on future fertility.

\section{Effects of chemotherapy on testicular function}

Chemotherapy can have a wide range of impact on testicular function and male fertility. Similarly to females, the effect of chemotherapy administration is age-dependent. Chromosomal abnormalities in spermatocytes may be detectable up to 24 months after cessation of treatment in Hodgkin's lymphoma patients. ${ }^{120}$ Alkylating agents, such as cyclophosphamide, chlorambucil, procarbazine, and busulfan, are associated with the greatest risk of gonadotoxicity. Similarly, platinum-based agents also confer a high risk of impaired gonadal function in males. ${ }^{128}$ Alkylating agents impede spermatogenesis in a dose-dependent manner. ${ }^{129}$ Cyclophosphamide administered at smaller doses of $7.5-9 \mathrm{~g} / \mathrm{m}^{2}$ has been shown to impair sperm function, and dosages over $10 \mathrm{~g} / \mathrm{m}^{2}$ are associated with a high risk of gonadal damage. Dosages greater than $19-20 \mathrm{~g} / \mathrm{m}^{2}$ typically result in permanent sterility (Table 4). ${ }^{19,129,130}$ Multiple smaller doses confer a greater risk to subsequent gonadal function than fewer larger doses of chemotherapy. ${ }^{131}$

\section{Effect of radiation on testicular function}

The extent of testicular injury sustained by radiation therapy is directly related both to the dose of radiation delivered and the underlying cell type. For instance, seminiferous tubules are sensitive to radiation doses as low as $0.1 \mathrm{~Gy}$, thereby resulting in temporary arrest of spermatogenesis. ${ }^{132}$
Table 4 Effects of chemotherapeutic agents on male fertility

\begin{tabular}{|c|c|}
\hline $\begin{array}{l}\text { Chemotherapy } \\
\text { (dose-to-cause effect) }\end{array}$ & Adverse effect on sperm count \\
\hline $\begin{array}{l}\text { Chlorambucil }\left(1.4 \mathrm{~g} / \mathrm{m}^{2}\right) \\
\text { Cyclophosphamide }\left(19 \mathrm{~g} / \mathrm{m}^{2}\right) \\
\text { Procarbazine }\left(4 \mathrm{~g} / \mathrm{m}^{2}\right) \\
\text { Melphalan }\left(140 \mathrm{mg} / \mathrm{m}^{2}\right) \\
\text { Cisplatin }\left(500 \mathrm{mg} / \mathrm{m}^{2}\right)\end{array}$ & $\begin{array}{l}\text { Prolonged or permanent } \\
\text { azoospermia }\end{array}$ \\
\hline $\begin{array}{l}\text { BCNU }\left(\mathrm{g} / \mathrm{m}^{2}\right) \\
\text { CCNU }\left(500 \mathrm{mg} / \mathrm{m}^{2}\right) \\
\text { Busulfan }\left(600 \mathrm{mg} / \mathrm{m}^{2}\right) \\
\text { Ifosfamide }\left(42 \mathrm{~g} / \mathrm{m}^{2}\right) \\
\text { BCNU }\left(300 \mathrm{mg} / \mathrm{m}^{2}\right) \\
\text { Nitrogen mustard } \\
\text { Actinomycin D }\end{array}$ & $\begin{array}{l}\text { Azoospermia in adulthood if treated } \\
\text { before puberty } \\
\text { Azoospermia likely, and are often } \\
\text { given with other highly sterilizing } \\
\text { agents, adding to the effect }\end{array}$ \\
\hline $\begin{array}{l}\text { Doxorubicin }\left(770 \mathrm{mg} / \mathrm{m}^{2}\right) \\
\text { Thiotepa }\left(400 \mathrm{mg} / \mathrm{m}^{2}\right) \\
\text { Cytarabine }\left(1 \mathrm{~g} / \mathrm{m}^{2}\right) \\
\text { Vinblastine }\left(50 \mathrm{~g} / \mathrm{m}^{2}\right) \\
\text { Vincristine }\left(8 \mathrm{~g} / \mathrm{m}^{2}\right)\end{array}$ & $\begin{array}{l}\text { When used alone, cause only } \\
\text { temporary reduction in sperm } \\
\text { count; in conjunction with above } \\
\text { agents, may be additive in causing } \\
\text { azoospermia }\end{array}$ \\
\hline $\begin{array}{l}\text { Amsacrine } \\
\text { Bleomycin } \\
\text { Dacarbazine } \\
\text { Daunorubicin } \\
\text { Epirubicin } \\
\text { Etoposide } \\
\text { Fludarabine } \\
\text { Fluorouracil } \\
\text { 6-Mercaptopurine } \\
\text { Methotrexate } \\
\text { Mitoxantrone } \\
\text { Thioguanine }\end{array}$ & $\begin{array}{l}\text { When used in conventional } \\
\text { regimens, cause only temporary } \\
\text { reductions in sperm count; in } \\
\text { conjunction with above agents, may } \\
\text { be additive in causing azoospermia }\end{array}$ \\
\hline
\end{tabular}

Note: Data from Devita et al. ${ }^{19}$

Abbreviations: $\mathrm{BCNU}$, bis-chloroethylnitrosourea (carmustine); $\mathrm{CCNU}$, I-(2-chloroethyl)-3-cyclohexyl-I-nitrosourea (lomustine).

Azoospermia has been reported at radiation doses of $0.65 \mathrm{~Gy}$, with doses of $1 \mathrm{~Gy}, 2-3 \mathrm{~Gy}$, and 4-6 Gy causing azoospermia lasting 9-18 months, 30 months, and 5 years to permanently, respectively. ${ }^{132-134}$

Radiation may also directly damage other testicular cell types, including sperms themselves. Exposure to radiotherapy has been known to cause DNA fragmentation in sperm, which may have a negative impact on future fertility. ${ }^{135}$ As previously mentioned, Leydig cells appear to be less susceptible to radiotherapy-induced damage. Radiation doses as high as 20 Gy in prepubertal males and 30 Gy in postpubertal males are required to induce damage to Leydig cells, and thereby clinical hypogonadism. ${ }^{136}$

In addition to the dose, testicular function is also directly affected by increasing the fractionation of ionizing radiotherapy. Increasing fractionation may lead to repeated sustained injury to testicular tissue and spermatogonia, causing an inability to repair and regenerate the reserve stem cell population. ${ }^{137,138}$ 


\section{Fertility-preservation options in males}

Similarly to females, the ability to preserve fertility in males is dependent upon the age at presentation. Approximately $20 \%$ of males at Tanner stage III or above with testicular volumes greater than $10 \mathrm{~mL}$ have the ability to provide sperm for cryopreservation. ${ }^{139}$ Prepubertal status in males, similarly to females, represents unique challenges, as the hypothalamic-pituitary-gonadal axis has not been activated. Currently, there are no widely accepted options for fertility preservation in prepubertal males.

\section{Ejaculated sperm cryopreservation}

Sperm cryopreservation is a well-established procedure utilized for fertility preservation in postpubertal male patients undergoing gonadotoxic therapy. Sperm cryopreservation is achieved through semen collection by masturbation prior to the initiation of chemoradiation. Two to three samples are typically collected, due to frequently reduced semen quality in cancer patients, and samples are obtained prior to cancer treatment to ensure optimal DNA integrity and sperm quality. ${ }^{140}$ Furthermore, in addition to preserving future fertility, many patients have reported that sperm banking is a method of coping with their malignancy, even if the samples remain unused. ${ }^{141}$ Sperm banking may provide a sense of security and reassurance of the future to these patients. While all patients undergoing gonadotoxic therapy should be offered sperm cryopreservation, some patients will be able to recover from gonadotoxic insult and recover sufficient levels of spermatogenesis posttreatment to sustain normal fertility. ${ }^{142}$

Some postpubertal males will not be able to provide semen samples through masturbatory ejaculation due to anxiety or medical problems, such as hypogonadism, neurologic impairment, diabetes, pain, etc. Fortunately, there are other methods available to obtain adequate sperm samples in such cases. For instance, there may be utility in administration of phosphodiesterase type 5 inhibitors, due to their known efficacy in erectile dysfunction. ${ }^{143}$ Other modalities used in this group of patients include penile vibratory stimulation (PVS) and electroejaculation. ${ }^{144}$ PVS may be beneficial for obtaining sperm in patients with an abnormal ejaculatory reflex, such as those with neurologic impairment, provided that the sacral reflex arc is intact. In PVS, a vibrator is placed against the penis and mechanical stimulation is used to induce ejaculation in patients who are unable to achieve ejaculation physiologically. Conversely, electroejaculation is a more invasive procedure involving placement of a probe containing electrodes in the patient's rectum and is utilized in patients with a compromised sacral reflex arc. Electric stimulation is subsequently delivered to the prostate and seminal vesicles to cause the emission of semen in patients with neurologic injury. This technique has also successfully been used in adolescents for fertility preservation. ${ }^{145}$ Due to the invasive nature of this procedure, it must be conducted under anesthesia to minimize patient discomfort. ${ }^{146}$

Patients suffering from retrograde ejaculation, due to a myriad of causes including surgical or radiation injury to the bladder neck and autonomic nerves or due to the use of certain medications, such as antidepressants, may be candidates for medical therapy with sympathomimetics, such as pseudoephedrine and $\alpha$-agonists. Alternatively, urine collection and processing in these men will often result in adequate sperm counts for cryopreservation. ${ }^{147}$

Patients with baseline severe oligospermia present unique challenges. Often, aspiration and surgical extraction of sperm may be undertaken in these patients. Options for sperm aspiration include percutaneous epididymal sperm aspiration, microsurgical epididymal sperm aspiration (MESA), and testicular sperm aspiration (TESA). Options for surgical extraction involve testicular biopsy and subsequent testicular sperm extraction (TESE). Patients with both obstructive and nonobstructive azoospermia may undergo testicular tissue extraction and subsequent cryopreservation. At the time of desired childbearing, sperm may be isolated from thawed tissue and utilized for ART. ${ }^{148}$ Rates of paternity utilizing ART with cryopreserved sperm from former cancer patients are reported to be between $33 \%$ and $56 \%$. ${ }^{149}$ Furthermore, successful paternity has been documented in patients with sperm preserved for up to 28 years. ${ }^{150}$ Surgical procedures for sperm extraction require anesthesia, due to their invasive nature.

\section{Investigational modalities \\ $\mathrm{GnRH}$-agonist therapy}

Previous studies have examined the effects of GnRH-a therapy in patients undergoing gonadotoxic therapy. GnRH-a administration results in gonadotropin-dependent arrest of spermatogenesis, and as a result this have been utilized to mitigate gonadotoxic insult to testicular germ cells. ${ }^{151}$ Unfortunately, despite success in rodent-models, human studies have failed to show any protective effects of $\mathrm{GnRH}$-as on germ cells, likely due to the proliferation of germ cells through a gonadotropin-independent pathway. ${ }^{152}$

\section{Testicular tissue cryopreservation in prepubertal boys}

For prepubertal patients who have not initiated spermatogenesis, cryopreservation of testicular tissue through either cell 
suspension or whole tissue may be a possible option for fertility preservation. ${ }^{153}$ Tissue can be obtained through the techniques previously mentioned, including TESA, MESA, and TESE. Although prepubertal testicular tissue does not contain mature spermatozoa, it does demonstrate the presence of diploid spermatogonial stem cells, which have the capacity to differentiate into mature cells in an ideal microenvironment. ${ }^{154}$ Ideally, this tissue could be autotransplanted at a later time in order to resume spermatogenesis after the completion of gonadotoxic therapy. Indeed, some studies have demonstrated successful transplantation of testicular tissue in immunodeficient mice. ${ }^{155}$ Unfortunately, no studies in humans have demonstrated the ability to transform immature cryopreserved tissue into functional gametes for later use in ART. ${ }^{139}$ Therefore, this procedure is offered at some centers to prepubertal boys only on an investigational basis. ${ }^{60}$ Spermatogonial stem cell transplantation may prove to be another modality in the therapeutic arsenal in this patient population, due to its ability to initiate spermatogenesis. Animal studies in mice and rhesus monkeys with obliterated testicular function have demonstrated successful autologous transplantation of spermatogonial stem cells, with subsequent restoration of spermatogenesis. ${ }^{156,157}$ While no such success has been documented in humans to date, ongoing research in this area may render this option feasible in this patient population. ${ }^{158}$

\section{Interdisciplinary care team}

The American Society for Reproductive Medicine emphasizes the need for an interdisciplinary care team for these patients. This collaborative team may include oncologists, reproductive endocrinologists, urologists, and surgeons. ${ }^{60}$ Additionally, the immense burden placed on these patients not only to cope with their illness but also to make rapid decisions with regard to fertility preservation underscores the need for thorough patient counseling. Mental health professionals should be included in this "care team" in addition to financial counselors to assist with coping with financial burden. While oncologists may initially counsel patients on their options for fertility preservation, reproductive endocrinologists and urologists should be consulted as soon as possible after initial diagnosis. Effective communication is crucial between all care providers to ensure optimal and expeditious patient care.

\section{Conclusion}

The prevalence of lymphoma in young and reproductive-age patients underscores the need for effective fertility-preservation strategies. As the effects of gonadotoxic chemoradiation are variable depending on the type, dose, and age of the patient, individualized counseling is essential for optimal care of these patients. Well-established fertility-preservation strategies, such as embryo cryopreservation for females and sperm cryopreservation for males, may not be feasible in all patients. Therefore, there is a significant need for further research into investigational methods, such as IVM and testicular tissue cryopreservation, in order to provide the ability to procreate to all patients afflicted with such cancers as lymphomas.

\section{Disclosure}

The authors report no conflicts of interest in this work.

\section{References}

1. National Cancer Institute. SEER stat fact sheets: Hodgkin lymphoma. Available from: seer.cancer.gov/statfacts/html/hodg.html. Accessed October 29, 2014.

2. Green DM, Kawashima T, Stovall M, et al. Fertility of female survivors of childhood cancer: a report from the Childhood Cancer Survivor Study. J Clin Oncol. 2009;27(16):2677-2685.

3. Batlevi CL, Younes A. Novel therapy for Hodgkin lymphoma Hematology Am Soc Hematol Educ Program. 2013;2013:394-399.

4. Cultrera JL, Dalia SM. Diffuse large B-cell lymphoma: current strategies and future directions. Cancer Control. 2012;19(3):204-213.

5. Jagadeesh D, Smith MR. Novel targeted therapies in peripheral T cell lymphoma. Discov Med. 2013;15(85):367-378.

6. Kim SS, Lee JR, Jee BC, et al. Use of hormonal protection for chemotherapy-induced gonadotoxicity. Clin Obstet Gynecol. 2010; 53(4):740-752.

7. Kim SS. Assessment of long term endocrine function after transplantation of frozen-thawed human ovarian tissue to the heterotopic site: 10 year longitudinal follow-up study. J Assist Reprod Genet. 2012;29(6):489-493.

8. Molina JR, Barton DL, Loprinzi CL. Chemotherapy-induced ovarian failure: manifestations and management. Drug Saf. 2005;28(5):401-416.

9. Sklar CA, Mertens AC, Mitby P, et al. Premature menopause in survivors of childhood cancer: a report from the Childhood Cancer Survivor Study. J Natl Cancer Inst. 2006;98(13):890-896.

10. van der Kaaij MA, Heutte N, Meijnders P, et al. Parenthood in survivors of Hodgkin lymphoma: an EORTC-GELA general population casecontrol study. J Clin Oncol. 2012;30(31):3854-3863.

11. Barton SE, Najita JS, Ginsburg ES, et al. Infertility, infertility treatment, and achievement of pregnancy in female survivors of childhood cancer: a report from the Childhood Cancer Survivor Study cohort. Lancet Oncol. 2013;14(9):873-881.

12. Barton SE, Missmer SA, Berry KF, Ginsburg ES. Female cancer survivors are low responders and have reduced success compared with other patients undergoing assisted reproductive technologies. Fertil Steril. 2012;97(2):381-386.

13. Lobo RA. Early ovarian ageing: a hypothesis. What is early ovarian ageing? Hum Reprod. 2003;18(9):1762-1764.

14. Wallace WH, Kelsey TW. Human ovarian reserve from conception to the menopause. PLoS One. 2010;5(1):e8772.

15. Dang-Tan T, Franco EL. Diagnosis delays in childhood cancer: a review. Cancer. 2007;110(4):703-713.

16. Marieb EN, Hoehn K. Human Anatomy and Physiology. 7th ed. San Francisco: Benjamin Cummings; 2007.

17. Yu B, Douglas N, Ferin MJ, et al. Changes in markers of ovarian reserve and endocrine function in young women with breast cancer undergoing adjuvant chemotherapy. Cancer. 2010;116(9):2099-2105. 
18. Epstein RJ. Drug-induced DNA damage and tumor chemosensitivity. J Clin Oncol. 1990;8(12):2062-2084.

19. DeVita VT, Hellmann S, Rosenberg SA, editors. Cancer: Principles and Practice of Oncology. 7th ed. Philadelphia: Lippincott Williams \& Wilkins; 2005.

20. Meirow D, Dor J, Kaufman B, et al. Cortical fibrosis and bloodvessels damage in human ovaries exposed to chemotherapy. Potential mechanisms of ovarian injury. Hum Reprod. 2007;22(6):1626-1633.

21. Green DM, Sklar CA, Boice JD Jr, et al. Ovarian failure and reproductive outcomes after childhood cancer treatment: results from the childhood cancer survivor study. J Clin Oncol. 2009;27(14):2374-2381.

22. Meirow D. Ovarian injury and modern options to preserve fertility in female cancer patients treated with high dose radio-chemotherapy for hemato-oncological neoplasias and other cancers. Leuk Lymphoma. 1999;33(1-2):65-76.

23. Vatanen A, Wilhelmsson M, Borgström B, et al. Ovarian function after allogeneic hematopoietic stem cell transplantation in childhood and adolescence. Eur J Endocrinol. 2013;170(2):211-218.

24. Carter A, Robison LL, Francisco L, et al. Prevalence of conception and pregnancy outcomes after hematopoietic cell transplantation: report from the bone marrow transplant survivor study. Bone Marrow Transplant. 2006;37(11):1023-1029.

25. Elis A, Tevet A, Yerushalmi R, et al. Fertility status among women treated for aggressive non-Hodgkin's lymphoma. Leuk Lymphoma. 2006;47(4):623-627.

26. Seshadri T, Hourigan MJ, Wolf M, Mollee PN, Seymour JF. The effect of the hyper-CVAD chemotherapy regimen on fertility and ovarian function. Leuk Res. 2006;30(4):483-485.

27. Goldhirsch A, Gelber RD, Castiglione M. The magnitude of endocrine effects of adjuvant chemotherapy for premenopausal breast cancer patients. The International Breast Cancer Study Group. Ann Oncol. 1990;1(3):183-188.

28. Behringer K, Mueller H, Goergen $\mathrm{H}$, et al. Gonadal function and fertility in survivors after Hodgkin lymphoma treatment within the German Hodgkin Study Group HD13 to HD15 trials. J Clin Oncol. 2013;31(2): 231-239.

29. Koyama H, Wada T, Nishizawa Y, Iwanaga T, Aoki Y. Cyclophosphamide-induced ovarian failure and its therapeutic significance in patients with breast cancer. Cancer. 1977;39(4):1403-1409.

30. Chiarelli AM, Marrett LD, Darlington G. Early menopause and infertility in females after treatment for childhood cancer diagnosed in 1964-1988 in Ontario, Canada. Am J Epidemiol. 1999;150(3):245-254.

31. Pereyra Pacheco B, Méndez Ribas JM, Milone G, et al. Use of GnRH analogs for functional protection of the ovary and preservation of fertility during cancer treatment in adolescents: a preliminary report. Gynecol Oncol. 2001;81(3):391-397.

32. Wallace WH, Thomson AB, Kelsey TW. The radiosensitivity of the human oocyte. Hum Reprod. 2003;18(1):117-121.

33. Lushbaugh CC, Casarett GW. The effects of gonadal irradiation in clinical radiation therapy: a review. Cancer. 1976;37(Suppl 2):1111-1125.

34. Damewood MD, Grochow LB. Prospects for fertility after chemotherapy or radiation for neoplastic disease. Fertil Steril. 1986;45(4):443-459.

35. Clough KB, Goffinet F, Labib A, et al. Laparoscopic unilateral ovarian transposition prior to irradiation: prospective study of 20 cases. Cancer. 1996;77(12):2638-2645.

36. Wallace WH, Thomson AB, Saran F, Kelsey TW. Predicting age of ovarian failure after radiation to a field that includes the ovaries. Int $J$ Radiat Oncol Biol Phys. 2005;62(3):738-744.

37. Thomson AB, Critchley HO, Kelnar CJ, Wallace WH. Late reproductive sequelae following treatment of childhood cancer and options for fertility preservation. Best Pract Res Clin Endocrinol Metab. 2002;16(2):311-334.

38. Meirow D, Nugent D. The effects of radiotherapy and chemotherapy on female reproduction. Hum Reprod Update. 2001;7(6):535-543.

39. Husseinzadeh N, Nahhas WA, Velkley DE, Whitney CW, Mortel R. The preservation of ovarian function in young women undergoing pelvic radiation therapy. Gynecol Oncol. 1984;18(3):373-379.
40. Bath LE, Critchley HO, Chambers SE, Anderson RA, Kelnar CJ, Wallace WH. Ovarian and uterine characteristics after total body irradiation in childhood and adolescence: response to sex steroid replacement. Br J Obstet Gynaecol. 1999;106(12):1265-1272.

41. Wallace WH, Shalet SM, Hendry JH, Morris-Jones PH, Gattamaneni HR. Ovarian failure following abdominal irradiation in childhood: the radiosensitivity of the human oocyte. Br J Radiol. 1989;62(743):995-998.

42. Fenig E, Mishaeli M, Kalish Y, Lishner M. Pregnancy and radiation. Cancer Treat Rev. 2001;27(1):1-7.

43. Robison LL, Green DM, Hudson M, et al. Long-term outcomes of adult survivors of childhood cancer. Cancer. 2005;104(Suppl 11): 2557-2564.

44. Green DM, Sklar CA, Boice JD Jr, et al. Ovarian failure and reproductive outcomes after childhood cancer treatment: results from the Childhood Cancer Survivor Study. J Clin Oncol. 2009;27(14):2374-2381.

45. De Sanctis V, Filippone FR, Alfo M, et al. Impact of different treatment approaches on pregnancy outcomes in 99 women treated for Hodgkin lymphoma. Int J Radiat Oncol Biol Phys. 2012;84(3):755-761.

46. Swerdlow AJ, Jacobs PA, Marks A, et al. Fertility, reproductive outcomes, and health of offspring, of patients treated for Hodgkin's disease: an investigation including chromosome examinations. $\mathrm{Br} \mathrm{J}$ Cancer. 1996;74(2):291-296.

47. Clowse ME, Behera MA, Anders CK, et al. Ovarian preservation by GnRH agonists during chemotherapy: a meta-analysis. JWomens Health (Larchmt). 2009;18(3):311-319.

48. Ataya KM, McKanna JA, Weintraub AM, Clark MR, LeMaire WJ. A luteinizing hormone-releasing hormone agonist for the prevention of chemotherapy-induced ovarian follicular loss in rats. Cancer Res. 1985;45(8):3651-3656.

49. Bokser L, Szende B, Schally AV. Protective effects of D-Trp6luteinising hormone-releasing hormone microcapsules against cyclophosphamide-induced gonadotoxicity in female rats. $\mathrm{Br}$ J Cancer. 1990;61(6):861-865.

50. Blumenfeld Z. Ovarian cryopreservation versus ovarian suppression by GnRH analogues: primum non nocere. Hum Reprod. 2004;19(8): 1924-1925.

51. Del Mastro L, Giraudi S, Levaggi A, Pronzato P. Medical approaches to preservation of fertility in female cancer patients. Expert Opin Pharmacother. 2011;12(3):387-396.

52. Blumenfeld Z, Katz G, Evron A. 'An ounce of prevention is worth a pound of cure': the case for and against GnRH-agonist for fertility preservation. Ann Oncol. 2014;25(9):1719-1728.

53. Ben-Aharon I, Gafter-Gvili A, Leibovici L, Stemmer SM. Pharmacological interventions for fertility preservation during chemotherapy: a systematic review and meta-analysis. Breast Cancer Res Treat. 2010;122(3):803-811.

54. Bedaiwy MA, Abou-Setta AM, Desai N, et al. Gonadotropin-releasing hormone analog cotreatment for preservation of ovarian function during gonadotoxic chemotherapy: a systematic review and meta-analysis. Fertil Steril. 2011;95(3):906-914. e1-e4.

55. Chen H, Li J, Cui T, Hu L. Adjuvant gonadotropin-releasing hormone analogues for the prevention of chemotherapy induced premature ovarian failure in premenopausal women. Cochrane Database Syst Rev. 2011;(11):CD008018.

56. Yang B, Shi W, Yang J, et al. Concurrent treatment with gonadotropinreleasing hormone agonists for chemotherapy-induced ovarian damage in premenopausal women with breast cancer: a meta-analysis of randomized controlled trials. Breast. 2013;22(2):150-157.

57. Wang C, Chen M, Fu F, Huang M. Gonadotropin-releasing hormone analog cotreatment for the preservation of ovarian function during gonadotoxic chemotherapy for breast cancer: a meta-analysis. PLoS One. 2013;8(6):e66360.

58. Sonmezer M, Oktay K. Fertility preservation in female patients. Hum Reprod Update. 2004;10(3):251-266.

59. Loren AW, Mangu PB, Beck LN, et al. Fertility preservation for patients with cancer: American Society of Clinical Oncology clinical practice guideline update. J Clin Oncol. 2013;31(19):2500-2510. 
60. Practice Committee of American Society for Reproductive Medicine. Fertility preservation in patients undergoing gonadotoxic therapy or gonadectomy: a committee opinion. Fertil Steril. 2013;100(5):1214-1223.

61. Birgegard G. Managing anemia in lymphoma and multiple myeloma. Ther Clin Risk Manag. 2008;4(2):527-539.

62. Howell SJ, Shalet SM. Fertility preservation and management of gonadal failure associated with lymphoma therapy. Curr Oncol Rep. 2002;4(5):443-452.

63. Bidziński M, Lemieszczuk B, Zieliński J. Evaluation of the hormonal function and features of the ultrasound picture of transposed ovary in cervical cancer patients after surgery and pelvic irradiation. Eur $J$ Gynaecol Oncol. 1993;14 Suppl:77-80.

64. Bisharah M, Tulandi T. Laparoscopic preservation of ovarian function: an underused procedure. Am J Obstet Gynecol. 2003;188(2):367-370.

65. Terenziani M, Piva L, Meazza C, Gandola L, Cefalo G, Merola M. Oophoropexy: a relevant role in preservation of ovarian function after pelvic irradiation. Fertil Steril. 2009;91(3):935. e15-e16.

66. Society for Assisted Reproductive Technology. Clinic summary report. 2012. Available from: https://www.sartcorsonline.com/rptCSR PublicMultYear.aspx?ClinicPKID=0. Accessed May 15, 2014

67. Son WY, Yoon SH, Yoon HJ, Lee SM, Lim JH. Pregnancy outcome following transfer of human blastocysts vitrified on electron microscopy grids after induced collapse of the blastocoele. Hum Reprod. 2003;18(1): 137-139.

68. Lawrenz B, Fehm T, von Wolff M, et al. Reduced pretreatment ovarian reserve in premenopausal female patients with Hodgkin lymphoma or non-Hodgkin-lymphoma - evaluation by using antimüllerian hormone and retrieved oocytes. Fertil Steril. 2012;98(1):141-144.

69. Ata B, Chian RC, Tan SL. Cryopreservation of oocytes and embryos for fertility preservation for female cancer patients. Best Pract Res Clin Obstet Gynaecol. 2010;24(1):101-112.

70. Katayama KP, Stehlik J, Kuwayama M, Kato O, Stehlik E. High survival rate of vitrified human oocytes results in clinical pregnancy. Fertil Steril. 2003;80(1):223-224.

71. Liebermann J, Tucker MJ, Sills ES. Cryoloop vitrification in assisted reproduction: analysis of survival rates in $>1000$ human oocytes after ultra-rapid cooling with polymer augmented cryoprotectants. Clin Exp Obstet Gynecol. 2003;30(2-3):125-129.

72. Yoon TK, Kim TJ, Park SE, et al. Live births after vitrification of oocytes in a stimulated in vitro fertilization-embryo transfer program. Fertil Steril. 2003;79(6):1323-1326.

73. Cobo A, Vajta G, Remohi J. Vitrification of human mature oocytes in clinical practice. Reprod Biomed Online. 2009;19 Suppl 4:4385.

74. Cobo A, Meseguer M, Remohi J, Pellicer A. Use of cryo-banked oocytes in an ovum donation programme: a prospective, randomized, controlled, clinical trial. Hum Reprod. 2010;25(9):2239-2246.

75. Schmidt KT, Andersen CY. Recommendations for fertility preservation in patients with lymphomas. J Assist Reprod Genet. 2012;29(6): 473-477.

76. Porcu E, Fabbri R, Damiano G, Fratto R, Giunchi S, Venturoli S. Oocyte cryopreservation in oncological patients. Eur J Obstet Gynecol Reprod Biol. 2004;113 Suppl 1:S14-S16.

77. Practice Committees of American Society for Reproductive Medicine, Society for Assisted Reproductive Technology. Mature oocyte cryopreservation: a guideline. Fertil Steril. 2013;99(1):37-43.

78. Borini A, Levi Setti PE, Anserini P, et al. Multicenter observational study on slow-cooling oocyte cryopreservation: clinical outcome. Fertil Steril. 2010;94(5):1662-1668.

79. Donnez J, Jadoul P, Squifflet J, et al. Ovarian tissue cryopreservation and transplantation in cancer patients. Best Pract Res Clin Obstet Gynaecol. 2010;24(1):87-100.

80. Donnez J, Dolmans MM, Demylle D, et al. Livebirth after orthotopic transplantation of cryopreserved ovarian tissue. Lancet. 2004;364(9443): 1405-1410.

81. Oktay K, Oktem O. Ovarian cryopreservation and transplantation for fertility preservation for medical indications: report of an ongoing experience. Fertil Steril. 2010;93(3):762-768.
82. Silber S, Kagawa N, Kuwayama M, Gosden R. Duration of fertility after fresh and frozen ovary transplantation. Fertil Steril. 2010;94(6): 2191-2196.

83. Silber SJ. Ovary cryopreservation and transplantation for fertility preservation. Mol Hum Reprod. 2012;18(2):59-67.

84. Donnez J, Silber S, Andersen CY, et al. Children born after autotransplantation of cryopreserved ovarian tissue. a review of 13 live births. Ann Med. 2011;43(6):437-450.

85. Meirow D. Fertility preservation in cancer patients using stored ovarian tissue: clinical aspects. Curr Opin Endocrinol Diabetes Obes. 2008;15(6):536-547.

86. Ernst E, Bergholdt S, Jørgensen JS, Andersen CY. The first woman to give birth to two children following transplantation of frozen/thawed ovarian tissue. Hum Reprod. 2010;25(5):1280-1281.

87. Sánchez-Serrano M, Crespo J, Mirabet V, et al. Twins born after transplantation of ovarian cortical tissue and oocyte vitrification. Fertil Steril. 2010;93(1):268. e11-e13.

88. Dittrich R, Lotz L, Keck G, et al. Live birth after ovarian tissue autotransplantation following overnight transportation before cryopreservation. Fertil Steril. 2012;97(2):387-390.

89. Revel A, Laufer N, Ben Meir A, Lebovich M, Mitrani E. Micro-organ ovarian transplantation enables pregnancy: a case report. Hum Reprod. 2011;26(5):1097-1103.

90. Donnez J, Dolmans MM, Pellicer A, et al. Restoration of ovarian activity and pregnancy after transplantation of cryopreserved ovarian tissue: a review of 60 cases of reimplantation. Fertil Steril. 2013;99(6):1503-1513.

91. Mazur P. The role of intracellular freezing in the death of cells cooled at supraoptimal rates. Cryobiology. 1977;14(3):251-272.

92. Sonmezer M, Oktay K. Orthotopic and heterotopic ovarian tissue transplantation. Best Pract Res Clin Obstet Gynaecol. 2010;24(1): 113-126.

93. McLaren JF, Bates GW. Fertility preservation in women of reproductive age with cancer. Am J Obstet Gynecol. 2012;207(6):455-462.

94. Jadoul P, Dolmans MM, Donnez J. Fertility preservation in girls during childhood: is it feasible, efficient and safe and to whom should it be proposed? Hum Reprod Update. 2010;16(6):617-630.

95. Oktay K. Evidence for limiting ovarian tissue harvesting for the purpose of transplantation to women younger than 40 years of age. J Clin Endocrinol Metab. 2002;87(4):1907-1908.

96. Dolmans MM, Marinescu C, Saussoy P, Van Langendonckt A, Amorim C, Donnez J. Reimplantation of cryopreserved ovarian tissue from patients with acute lymphoblastic leukemia is potentially unsafe. Blood. 2010;116(16):2908-2914.

97. Bastings L, Beerendonk CC, Westphal JR, et al. Autotransplantation of cryopreserved ovarian tissue in cancer survivors and the risk of reintroducing malignancy: a systematic review. Hum Reprod Update. 2013;19(5):483-506.

98. Jeremias E, Bedaiwy MA, Gurunluoglu R, Biscotti CV, Siemionow M, Falcone T. Heterotopic autotransplantation of the ovary with microvascular anastomosis: a novel surgical technique. Fertil Steril. 2002; 77(6):1278-1282.

99. Cha KY, Koo JJ, Ko JJ, Choi DH, Han SY, Yoon TK. Pregnancy after in vitro fertilization of human follicular oocytes collected from nonstimulated cycles, their culture in vitro and their transfer in a donor oocyte program. Fertil Steril. 1991;55(1):109-113.

100. Cha KY, Chian RC. Maturation in vitro of immature human oocytes for clinical use. Hum Reprod Update. 1998;4(2):103-120.

101. Trounson A, Wood C, Kausche A. In vitro maturation and the fertilization and developmental competence of oocytes recovered from untreated polycystic ovarian patients. Fertil Steril. 1994;62(2): 353-362.

102. Practice Committees of the American Society for Reproductive Medicine and the Society for Assisted Reproductive Technology. In vitro maturation: a committee opinion. Fertil Steril. 2013;99(3):663-666.

103. Marhhom E, Cohen I. Fertility preservation options for women with malignancies. Obstet Gynecol Surv. 2007;62(1):58-72. 
104. Anderson RA, Wallace WH, Baird DT. Ovarian cryopreservation for fertility preservation: indications and outcomes. Reproduction. 2008;136(6):681-689.

105. Ptak G, Loi P, Dattena M, Tischner M, Cappai P. Offspring from one-month-old lambs: studies on the developmental capability of prepubertal oocytes. Biol Reprod. 1999;61(6):1568-1574.

106. Iwamatsu T, Yanagimachi R. Maturation in vitro of ovarian oocytes of prepubertal and adult hamsters. J Reprod Fertil. 1975;45(1):83-90.

107. Bredkjaer HE, Grudzinskas JG. Cryobiology in human assisted reproductive technology. Would Hippocrates approve? Early Pregnancy. 2001;5(3):211-213.

108. Nagai T. The improvement of in vitro maturation systems for bovine and porcine oocytes. Theriogenology. 2001;55(6):1291-1301.

109. Funahashi H, Day BN. Advances in in vitro production of pig embryos. J Reprod Fertil Suppl. 1997;52:271-283.

110. Morton KM. Developmental capabilities of embryos produced in vitro from prepubertal lamb oocytes. Reprod Domest Anim. 2008;43 Suppl 2: 137-143.

111. Shirazi A, Shams-Esfandabadi N, Ahmadi E, Jadidi M, Heidari B. Pregnancy rate following transfer of in vitro produced lamb derived embryos in two embryonic stages. Pak J Biol Sci. 2008;11(6):938-941.

112. Jimenez-Macedo AR, Paramio MT, Anguita B, et al. Effect of ICSI and embryo biopsy on embryo development and apoptosis according to oocyte diameter in prepubertal goats. Theriogenology. 2007;67(8): 1399-1408.

113. Müller J, Skakkebaek NE. Quantification of germ cells and seminiferous tubules by stereological examination of testicles from 50 boys who suffered from sudden death. Int J Androl. 1983;6(2):143-156.

114. Ehmcke J, Luetjens CM, Schlatt S. Clonal organization of proliferating spermatogonial stem cells in adult males of two species of non-human primates, Macaca mulatta and Callithrix jacchus. Biol Reprod. 2005;72(2):293-300.

115. Sriraman V, Sairam MR, Jagannadha Rao A. Evaluation of relative role of $\mathrm{LH}$ and FSH in restoration of spermatogenesis using etha nedimethylsulphonate-treated adult rats. Reprod Biomed Online. 2004;8(2):167-174.

116. Lass A, Akagbosu F, Abusheikha N, et al. A programme of semen cryopreservation for patients with malignant disease in a tertiary infertility centre: lessons from 8 years' experience. Hum Reprod. 1998;13(11):3256-3261.

117. Hayat MJ, Howlader N, Reichman ME, Edwards BK. Cancer statistics, trends, and multiple primary cancer analyses from the surveillance, epidemiology, and end results (SEER) program. Oncologist. 2007; 12(1):20-37.

118. Rueffer U, Breuer K, Josting A, et al. Male gonadal dysfunction in patients with Hodgkin's disease prior to treatment. Ann Oncol. 2001;12(9):1307-1311.

119. de Luyk N, Pozzato G, Ricci G, et al. Pre-treatment and post-treatment fertility in young male patients affected by Hodgkin and non-Hodgkin lymphoma. Arch Ital Urol Androl. 2012;84(3):141-145.

120. Tempest HG, Ko E, Chan P, Robaire B, Rademaker A, Martin RH. Sperm aneuploidy frequencies analysed before and after chemotherapy in testicular cancer and Hodgkin's lymphoma patients. Hum Reprod. 2008;23(2):251-258.

121. Vigersky RA, Chapman RM, Berenberg J, Glass AR. Testicular dysfunction in untreated Hodgkin's disease. Am J Med. 1982;73(4): 482-486.

122. Meseguer M, Garrido N, Remohi J, et al. Testicular sperm extraction (TESE) and ICSI in patients with permanent azoospermia after chemotherapy. Hum Reprod. 2003;18(6):1281-1285.

123. de Rooij DG, van de Kant HJ, Dol R, et al. Long-term effects of irradiation before adulthood on reproductive function in the male rhesus monkey. Biol Reprod. 2002;66(2):486-494.

124. van Casteren NJ, van der Linden GH, Hakvoort-Cammel FG, Hahlen K, Dohle GR, van den Heuvel-Eibrink MM. Effect of childhood cancer treatment on fertility markers in adult male long-term survivors. Pediatr Blood Cancer. 2009;52(1):108-112.
125. van Alphen MM, van de Kant HJ, de Rooij DG. Repopulation of the seminiferous epithelium of the rhesus monkey after $\mathrm{X}$ irradiation. Radiat Res. 1988;113(3):487-500.

126. Sklar C. Reproductive physiology and treatment-related loss of sex hormone production. Med Pediatr Oncol. 1999;33(1):2-8.

127. Hou M, Eriksson E, Svechnikov K, et al. Bortezomib treatment causes long-term testicular dysfunction in young male mice. Mol Cancer. 2014;13:155.

128. Waxman J. Chemotherapy and the adult gonad: a review. $J R$ Soc Med. 1983;76(2):144-148.

129. Meistrich ML, Wilson G, Brown BW, da Cunha MF, Lipshultz LI. Impact of cyclophosphamide on long-term reduction in sperm count in men treated with combination chemotherapy for Ewing and soft tissue sarcomas. Cancer. 1992;70(11):2703-2712.

130. Ridola V, Fawaz O, Aubier F, et al. Testicular function of survivors of childhood cancer: a comparative study between ifosfamide- and cyclophosphamide-based regimens. Eur J Cancer. 2009;45(5): 814-818.

131. Nurmio M, Keros V, Lahteenmaki P, Salmi T, Kallajoki M, Jahnukainen K. Effect of childhood acute lymphoblastic leukemia therapy on spermatogonia populations and future fertility. $J$ Clin Endocrinol Metab. 2009;94(6):2119-2122.

132. Pryzant RM, Meistrich ML, Wilson G, Brown B, McLaughlin P. Long-term reduction in sperm count after chemotherapy with and without radiation therapy for non-Hodgkin's lymphomas. J Clin Oncol. 1993;11(2):239-247.

133. Sandeman TF. The effects of $X$ irradiation on male human fertility. Br J Radiol. 1966;39(468):901-907.

134. Hahn EW, Feingold SM, Simpson L, Batata M. Recovery from aspermia induced by low-dose radiation in seminoma patients. Cancer. 1982;50(2):337-340.

135. González-Marin C, Gosálvez J, Roy R. Types, causes, detection and repair of DNA fragmentation in animal and human sperm cells. Int $J$ Mol Sci. 2012;13(11):14026-14052.

136. Shalet SM, Tsatsoulis A, Whitehead E, Read G. Vulnerability of the human Leydig cell to radiation damage is dependent upon age. J Endocrinol. 1989;120(1):161-165.

137. Ash $\mathrm{P}$. The influence of radiation on fertility in man. Br J Radiol. 1980;53(628):271-278.

138. Centola GM, Keller JW, Henzler M, Rubin P. Effect of low-dose testicular irradiation on sperm count and fertility in patients with testicular seminoma. J Androl. 1994;15(6):608-613.

139. Trost L, Brannigan R. Fertility preservation in males. In: Gracia C, Woodruff TK. Oncofertility Medical Practice: Clinical Issues and Implementation. New York: Springer; 2012:27-50.

140. Lee SJ, Schover LR, Partridge AH, et al. American Society of Clinical Oncology recommendations on fertility preservation in cancer patients. J Clin Oncol. 2006;24(18):2917-2931.

141. Saito K, Suzuki K, Iwasaki A, Yumura Y, Kubota Y. Sperm cryopreservation before cancer chemotherapy helps in the emotional battle against cancer. Cancer. 2005;104(3):521-524.

142. Fossa SD, Melvik JE, Juul NO, Pettersen EO, Theodorsen L. DNA flow cytometry in sperm cells from unilaterally orchiectomized patients with testicular cancer before further treatment. Cytometry. 1989;10(3):345-350.

143. Tur-Kaspa I, Segal S, Moffa F, Massobrio M, Meltzer S. Viagra for temporary erectile dysfunction during treatments with assisted reproductive technologies. Hum Reprod. 1999;14(7):1783-1784.

144. Brackett NL. Semen retrieval by penile vibratory stimulation in men with spinal cord injury. Hum Reprod Update. 1999;5(3): 216-222.

145. Hovav Y, Dan-Goor M, Yaffe H, Almagor M. Electroejaculation before chemotherapy in adolescents and young men with cancer. Fertil Steril. 2001;75(4):811-813.

146. Ohl DA, Wolf LJ, Menge AC, et al. Electroejaculation and assisted reproductive technologies in the treatment of anejaculatory infertility. Fertil Steril. 2001;76(6):1249-1255. 
147. Ohl DA, Quallich SA, Sønksen J, Brackett NL, Lynne CM. Anejaculation and retrograde ejaculation. Urol Clin North Am. 2008;35(2):211-220, viii.

148. Prins GS, Dolgina R, Studney P, Kaplan B, Ross L, Niederberger C. Quality of cryopreserved testicular sperm in patients with obstructive and nonobstructive azoospermia. J Urol. 1999;161(5):1504-1508.

149. van Casteren NJ, van Santbrink EJ, van Inzen W, Romijn JC, Dohle GR. Use rate and assisted reproduction technologies outcome of cryopreserved semen from 629 cancer patients. Fertil Steril. 2008;90(6): 2245-2250

150. Feldschuh J, Brassel J, Durso N, Levine A. Successful sperm storage for 28 years. Fertil Steril. 2005;84(4):1017.

151. Meistrich ML, Shetty G. Hormonal suppression for fertility preservation in males and females. Reproduction. 2008;136(6):691-701.

152. Shetty G, Meistrich ML. Hormonal approaches to preservation and restoration of male fertility after cancer treatment. J Natl Cancer Inst Monogr. 2005;(34):36-39.
153. Brinster RL. Male germline stem cells: from mice to men. Science. 2007;316(5823):404-405.

154. Brook PF, Radford JA, Shalet SM, Joyce AD, Gosden RG. Isolation of germ cells from human testicular tissue for low temperature storage and autotransplantation. Fertil Steril. 2001;75(2):269-274.

155. Shinohara T, Kato M, Takehashi M, et al. Rats produced by interspecies spermatogonial transplantation in mice and in vitro microinsemination. Proc Natl Acad Sci U S A. 2006;103(37):13624-13628.

156. Brinster RL, Zimmermann JW. Spermatogenesis following male germ-cell transplantation. Proc Natl Acad Sci U S A. 1994;91(24): 11298-11302.

157. Hermann BP, Sukhwani M, Winkler F, et al. Spermatogonial stem cell transplantation into rhesus testes regenerates spermatogenesis producing functional sperm. Cell Stem Cell. 2012;11(5):715-726.

158. Sadri-Ardekani H, Atala A. Testicular tissue cryopreservation and spermatogonial stem cell transplantation to restore fertility: from bench to bedside. Stem Cell Res Ther. 2014;5(3):68.

\section{Publish your work in this journal}

Blood and Lymphatic Cancer: Targets and Therapy is an international, peer-reviewed, open access journal focusing on blood and lymphatic cancer research, identification of therapeutic targets and the optimal use of preventative and integrated treatment interventions to achieve improved outcomes, enhanced survival and quality of life for the cancer patient. The manuscript management system is completely online and includes a very quick and fair peer-review system. Visit http://www.dovepress.com/testimonials.php to read real quotes from published authors.

Submit your manuscript here: http://www.dovepress.com/blood-and-lymphatic-cancer-targets-and-therapy-journal 